The analysis suggests that climate modellers could improve model performance by incorporating more realistic treatments of ozone chemistry and aerosols.

Proc. Natl Acad. Sci. USA http://dx.doi.org/10.1073/ pnas.1210514109 (2012)

\section{NEUROSCIENCE}

\section{Simulated brain solves problems}

A computer model of the brain containing 2.5 million virtual neurons exhibits complex behaviours such as recognizing numerical patterns and doing simple arithmetic.

Chris Eliasmith and his team at the University of Waterloo, Canada, have developed a brain model that can 'see' images and perform tasks, writing out answers with a robotic arm. The model simulates the physiology of each of its 'neurons', such as the spikes of electricity that flow through them. The cells are divided into groups corresponding to specific parts of the brain that process images, control movements and store shortterm memories. These regions are wired together, allowing the 'brain' to perform at least eight different tasks.

However, the model is limited: it is slow, simulates only a small fraction of the human brain and cannot learn completely new tasks or deal with inputs beyond the ten numerals.

Science 338, 1202-1205 (2012)

For a longer story on this research, see go.nature.com/edkkvr

\section{GEOLOGY}

\section{Tohoku quake's predecessor}

Japan's Sendai region, which was devastated by a magnitude- 9 earthquake and a tsunami in 2011, experienced similar events in AD $869-$ and such disasters could occur in the area more often than previously thought.

Seismic assessments have typically underestimated the earthquake hazard for the Sendai area, in part because of uncertainty surrounding the size of the 869 Jogan earthquake and the frequency of large earthquakes in the region. Yuki Sawai and his colleagues at the Geological Survey of Japan in Tsukuba studied sediment samples from 399 locations along the coast near Sendai, looking for tsunami deposits and signs of seismic activity. They found deposits associated with the Jogan earthquake stretching at least 1.5 kilometres inland - farther than deposits from tsunamis that occurred between 869 and 2011 . Earthquake modelling suggests that the Jogan event had a magnitude of 8.4 or higher. Moreover, the authors estimate that such an event could occur every 500-800 years.

The findings, which were reported in preliminary form before 2011, might have improved earthquake hazard assessment for the Sendai region, the authors say.

Geophys. Res. Lett. http://dx.doi. org/10.1029/2012GL053692 (2012)

\section{CLIMATE CHANGE}

\section{Ever faster polar ice loss}

An analysis of dozens of studies on polar ice has yielded the most accurate estimate yet of ice-sheet melting. Between them, Antarctica and Greenland are now losing mass three times faster than they were 20 years ago, and Greenland alone is shedding ice at about five times the rate it was in the mid-1990s.

Previous melting estimates have been inconsistent. To address this uncertainty, Andrew Shepherd at the University of Leeds, UK, Erik Ivins at NASA's Jet Propulsion Laboratory in Pasadena, California, and their colleagues compared and combined four types of satellite data on ice-sheet mass. They found that, since 1992, the ice sheets have contributed more than 11 millimetres to

COMMUNITY CHOICE

The most viewed papers in science

\title{
Cheaters are bad for biofilms
}

HIGHLY READ
on royalsociety-
publishing.org
in October

Just as self-interest can hamper cooperation and fitness in human societies, the presence of 'cheater' microorganisms decreases the population fitness of tightknit bacterial communities.

Certain bacteria form organized assemblies known as biofilms by releasing small-molecule signals that trigger cellular aggregation. The films offer survival advantages, helping the microbes to resist antibiotics, for example. Researchers led by Stephen Diggle at the University of Nottingham, UK, created biofilms consisting of varying proportions of cooperative Pseudomonas aeruginosa - a human pathogen - and a 'cheating' mutant that cannot respond to the aggregation signal but still benefits from being part of the biofilm. Biofilms containing more 'cheaters' grew more slowly and were less resistant to antibiotics than films with few or no cheaters.

Strategies that take advantage of the evolution of cheating pathogens may be useful in combating biofilms, which can cause persistent infections, the authors suggest.

Proc. R. Soc. B. 279, 4765-4771 (2012) sea-level rise - one-fifth of the total for that period.

The authors say that their estimates are two to three times more accurate than those from the latest report of the Intergovernmental Panel on Climate Change.

Science 338, 1183-1189 (2012)

For a longer story on this research, see go.nature.com/ydpp6a

\section{ECOLOGY}

\section{Night light helps} shorebird

Artificial lighting can harm wild creatures by disorientating them, but for some - such as the common redshank, a migratory shorebird - it can help.

Ross Dwyer at the University of Exeter in Penryn, UK, and his colleagues studied the bird (Tringa totanus; pictured) in an estuary near industrial sites in eastern Scotland. The researchers tagged the redshanks with posturesensitive radio transmitters, making it possible to measure how much time the birds spent with their heads down

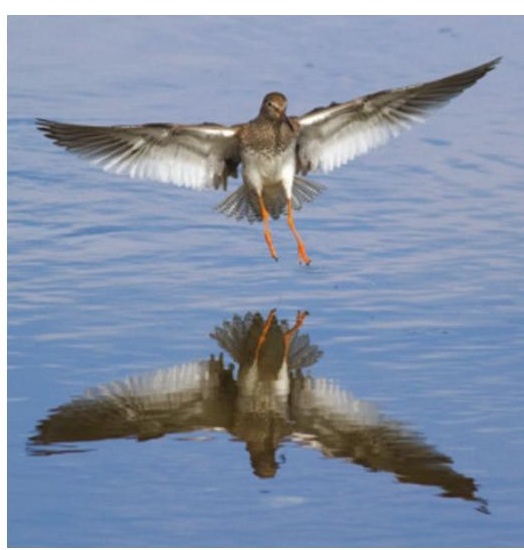

— sweeping through mud or sand to search for food - and up, stalking prey visually. The authors found that redshanks near artificial light spent more time visually stalking - which is more efficient than searching by touch - than those in darker areas, suggesting that the light improves the animal's foraging opportunities.

J. Anim. Ecol. http://dx.doi. org/10.1111/1365-2656.12012 (2012)

\section{DNATURE.COM}

For the latest research published by Naturevisit:

www.nature,com/latestresearch 